This item was submitted to Loughborough's Research Repository by the author.

Items in Figshare are protected by copyright, with all rights reserved, unless otherwise indicated.

\title{
Investigation of fully dense laser sintering of tool steel powder using a pulsed Nd:YAG (neodymium-doped yttrium aluminium garnet) laser
}

PLEASE CITE THE PUBLISHED VERSION

PUBLISHER

Professional Engineering Publishing / @ IMechE

VERSION

VoR (Version of Record)

LICENCE

CC BY-NC-ND 4.0

\section{REPOSITORY RECORD}

Su, W.-N., Poonjolai Erasenthiran, and Phill M. Dickens. 2019. "Investigation of Fully Dense Laser Sintering of Tool Steel Powder Using a Pulsed Nd:yag (neodymium-doped Yttrium Aluminium Garnet) Laser". figshare. https://hdl.handle.net/2134/4721. 
This item was submitted to Loughborough's Institutional Repository (https://dspace.lboro.ac.uk/) by the author and is made available under the following Creative Commons Licence conditions.

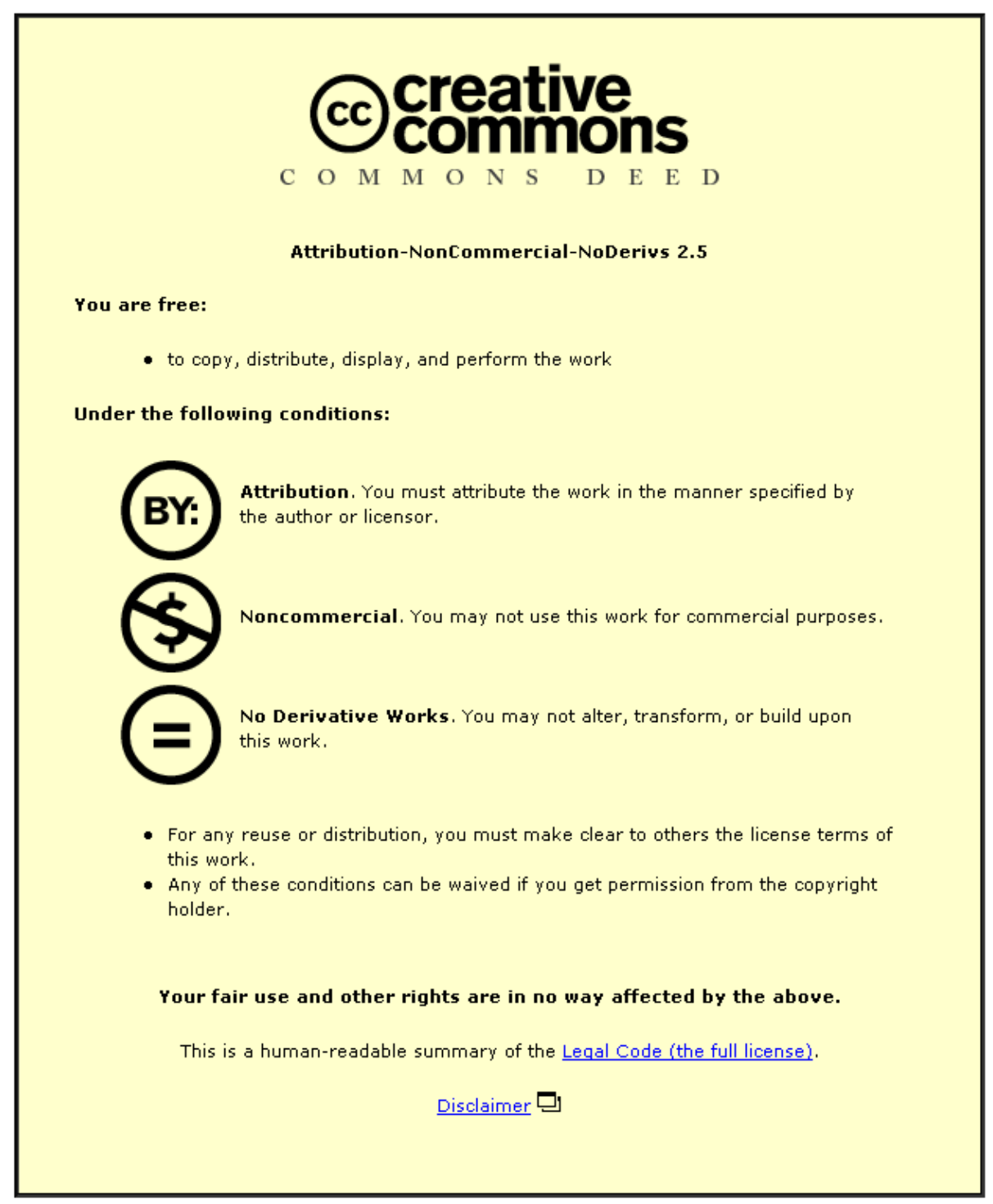

For the full text of this licence, please go to: http://creativecommons.org/licenses/by-nc-nd/2.5/ 


\title{
Investigation of fully dense laser sintering of tool steel powder using a pulsed Nd:YAG (neodymium-doped yttrium aluminium garnet) laser
}

\author{
W-N Su*, P Erasenthiran and $\mathbf{P}$ M Dickens
}

Rapid Manufacturing Research Group, Wolfson School of Mechanical and Manufacturing Engineering, Loughborough University, Loughborough, Leicestershire, UK

\begin{abstract}
A $550 \mathrm{~W}$ neodymium-doped yttrium aluminium garnet (Nd:YAG) pulsed laser was used in the solid freeform fabrication (SFF) process to form fully dense sintered parts. Tool steel powder was chosen due to its wide acceptance in the tool-making industry. Unlike many processes applying either thermoplastic binder or metals of low melting points in the powder mixture, this process enables a direct fusion of material to solid parts without a further post-processing step. This paper presents a methodology and the results of high-power laser sintering of tool steel powder. The investigation includes the effects of various process parameters on the fully dense laser sintering results on a single bead and single layer and the related scan strategy to build up solid cubes. This process could eventually produce pre-forms with complex material structures rather than finished tools or parts.
\end{abstract}

Keywords: laser sintering, Nd:YAG laser, tool steel, tooling, laser cladding

\section{INTRODUCTION}

Rapid tooling is moving towards manufacturing highperformance tools with material properties that cannot be obtained from conventional techniques. Rapid prototyping has significantly reduced lead times and costs for models in product development. A significant advantage of rapid prototyping is the ability to manufacture any geometry. Manufacturing shapes by adding layers of material is also being used for tools for various processes.

However, most of these tools are used for prototype quantities or require indirect processes to arrive at a metal tool. There is therefore a strong desire by companies for a process that manufactures metal tools directly using additive manufacturing techniques. A promising technique for producing metal tools directly is the use of laser sintering or the fusion of metal powders. There are a number of research organizations involved in work connected with laser sintering or laser

The MS was received on 19 February 2002 and was accepted after revision for publication on 15 October 2002.

* Corresponding author: Rapid M anufacturing Research Group, Wolfson School of Mechanical and Manufacturing Engineering, Loughborough University, Loughborough, Leicestershire LE11 3TU, UK. fusion of powders. These techniques are broadly split into three groups.

The first is indirect sintering, which is basically a lowtemperature system. This involves the use of a base metal powder and polymer mix binder component. The laser melts the polymer and binds the powder together. In order to fill the porosity, the parts produced need to go through an infiltration stage with bronze or copper. The second process route, binary phase sintering, involves the use of a composite powder blend containing two or more alloys. A low-energy laser beam (50-100 W) fuses low-melt temperature alloy in preference to highmelt temperature particles, the low-melt component acting as a matrix binding the part together [1]. The third, which is direct metal laser sintering (DMLS), is a combination of sintering and melting process which seeks to alleviate some of the problems apparent in the current techniques. This process involves the use of a high-power laser to fuse high-temperature powder with the aim of eliminating all internal porosity in order to obtain the highest density possible. The major problems associated with this technique are the strong surface forces that act on the melt pool, driving it towards a minimum surface energy state, which is spherical, leaving areas of porosity between melt tracks [2], hightemperature oxidation of the material [3] and high 
residual stresses $[\mathbf{4}, \mathbf{5}]$, which causes porosity in the completed parts.

All of the above work has involved laying down a powder bed and then scanning a laser spot across the surface of the material. The alternative is to use a powder feed into the laser spot, which is generally known as laser cladding or laser generating [6-10]. Work is being undertaken at several centres including Sandia National Laboratories in the United States and Fraunhofer-IPT in Aachen, Germany, using techniques and processes such as laser engineered net-shaping $\left(\text { LENS }^{\mathrm{TM}}\right)^{2}$ [11], directed light fabrication (DLF) [12], direct metal deposition (DMD) [13], shape deposition manufacturing (SDM) [14], controlled metal build-up and wire feed system [15]. Optomec Design Company in the United States is now marketing machines that use this powder feed system. There are advantages to both systems of applying powder. The powder bed system has the main advantage of being able to produce more complicated shapes where down-facing surfaces are involved. For example, it is possible to manufacture hollow shapes and an application for this in tooling is cooling channels. These cooling channels can conform to the shape of the tool surface and therefore provide more efficient heat transfer for processes such as injection moulding and die casting. Initial work on conformal cooling has been shown to reduce cycle times by 40 per cent and also to improve the quality of the parts [16].

The main benefit to be gained from producing tools from powder will be the ability to vary the material composition to increase the functionality of the tool using either a powder bed or powder feed system or a combination of both. This will be an advantage that conventional manufacturing techniques could never match. The obvious thing to do is to manufacture tool pre-forms with variable composition at critical locations and then use heat treatment and machining to finish the cavity. Therefore, residual stresses, surface finishing and accuracy is not an issue in this current work.

This work represents a preliminary phase in the development of a novel rapid layered manufacturing process for fully dense metal parts. A high-power $\mathrm{Nd}$ :YAG $(550 \mathrm{~W})$ laser was used to fuse tool steel powder of average size $150 \mu \mathrm{m}$ in order to achieve porosity-free parts to avoid infiltration, secondary sintering or hiping. This paper reports on the effect of

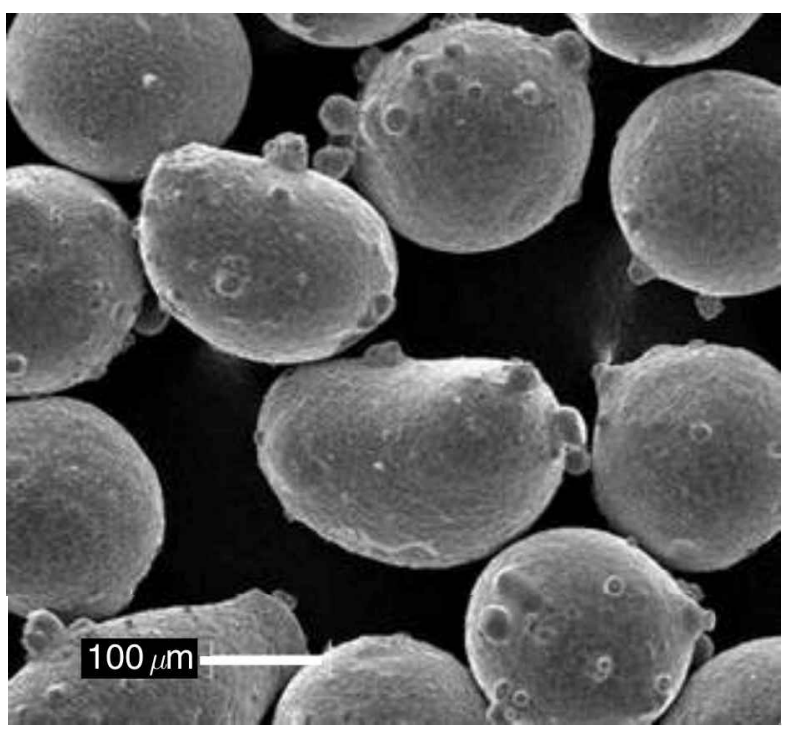

Fig. 1 Scanning electron micrograph of the tool steel powder

various process parameters, which influence the geometry of the scanned bead, and the scanning pattern strategy, which influences the geometry of a built layer and the porosity.

\section{EXPERIMENTAL METHODOLOGY}

\subsection{Tool steel powders}

The tool steel powders were supplied by Osprey Metals Limited and specified as the German standard WN 1.2367; AISI H10 is the nearest equivalent. The powders were seen to be generally spherical under scanning electron microscopy (SEM), as shown in Fig. 1. The green packing density of the tool steel powder was 0.56 by measuring the weight and volume and the tap density was 0.6 . The composition of the powder was analysed by energy dispersive X-ray (EDX) microanalysis and showed no trace of oxygen. The particle size analysis was executed using a Mastersize $S$ particle size analyser (Malvern Instruments Limited). The applied raw powder had a monodisperse size distribution, shown in Fig. 2. The measurements are summarized in Table 1.

Table 1 Particle size and composition of the tool steel powder

\begin{tabular}{lllllllll}
\hline Diameter at $50 \%$ of the cumulative undersize curve & & & \multicolumn{3}{c}{$138.95 \mu \mathrm{m}$} \\
\hline & $\mathrm{Fe}$ & $\mathrm{C}$ & $\mathrm{Si}$ & $\mathrm{Cr}$ & $\mathrm{Mo}$ & $\mathrm{Mn}$ & $\mathrm{V}$ \\
\hline As quoted by supplier (\%) & 89.37 & 0.37 & 0.85 & 5.07 & 2.98 & 0.70 & 0.66 \\
EDX average (\%) & 89.7 & - & 0.73 & 5.14 & 2.93 & 0.73 & 0.76 \\
\hline
\end{tabular}




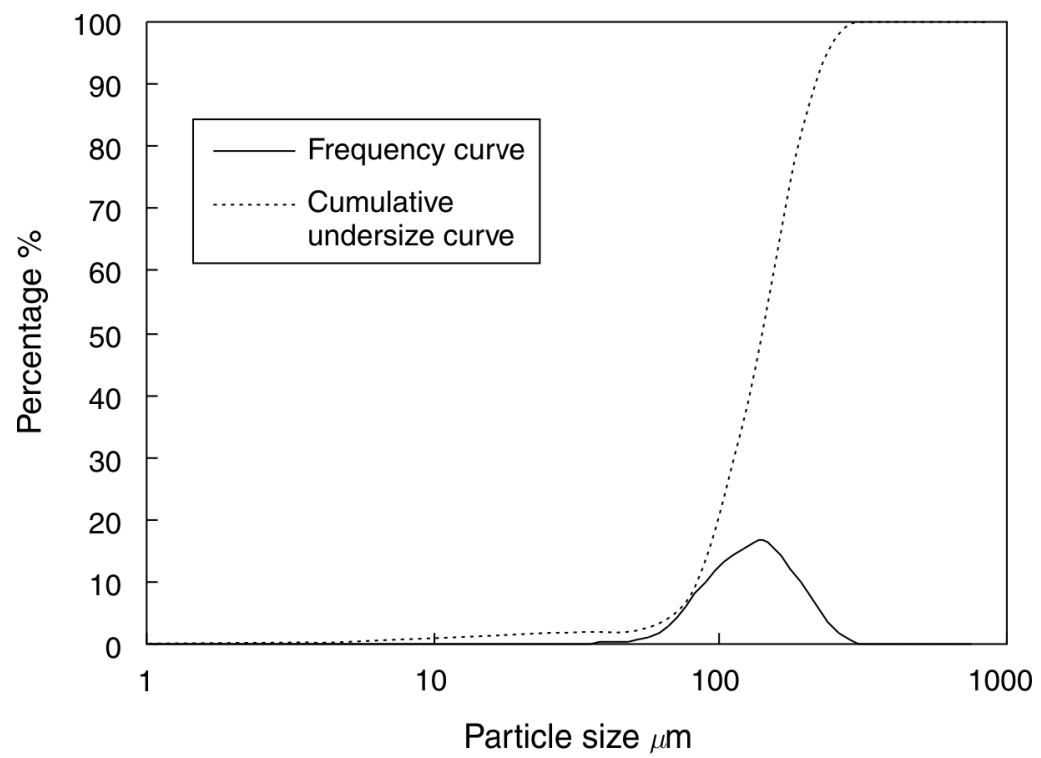

Fig. 2 Particle size distribution of the H10 tool steel powder

\subsection{System set-up}

A GSI Lumonics JK 701H Nd:YAG (neodymium-doped yttrium aluminium garnet) (wavelength $1.016 \mu \mathrm{m}$ ) pulsed laser with a maximum of $550 \mathrm{~W}$ was used. The laser beam was delivered by an optical fibre and had the advantage of more processing flexibility and a spot size relatively independent of applied laser power. The focused beam diameter was measured at $0.9 \mathrm{~mm}$.

The whole experiment was carried out in an inert gas shroud (Ar) with a minimum pressure of 2 bar in order to minimize possible surface oxidation. The gas flowrate was kept at 15 litre/min. The tool steel powder was prelayered with a thickness of $1 \mathrm{~mm}$ by a designed frame and manual levelling. No preheating was applied throughout the whole experiment.

To evaluate the effects of the various combinations of parameters on the fused beads, measurements of the surface features, including waviness and roughness, were carried out using a Laser Stylus RM600 (wavelength $780 \mathrm{~nm}$; maker: Rodenstock) containing a sensor and a sensor interface. The surface features were obtained with a resolution of $0.2 \mu \mathrm{m}$ by dynamic focusing of the laser beam and rapid interpretation of the lens position. Bead widths were measured by examining the digital photographs of the results and calibrating with a reference length.

\subsection{Laser variables}

A laser pulse width is also referred to as the pulse length or pulse duration. This is the time or duration of the pulse emitted by a pulsed laser typically expressed in milliseconds. Available pulse widths varied from 0.5 to
$20 \mathrm{~ms}$. Laser pulse energy measured in joules, ranging from 0.1 to $70 \mathrm{~J}$, is the total energy contained in a single laser pulse. The repetition rate varied up to $100 \mathrm{~Hz}$. The product of laser pulse energy and repetition rate gives the average laser power output with a maximum of $550 \mathrm{~W}$. The maximum feed rate of the $X / Y$ table was $20 \mathrm{~m} / \mathrm{min}$ in both directions and the movement could be programmed with common computer numerical control (CNC) commands (G-codes). The applied pulses were simple square pulses.

Specific energy density describes the distribution of laser energy in a scanned area along a linear movement and is defined by dividing laser power by velocity and the beam diameter. Sometimes it is found that scan spacing instead of the beam diameter is used.

\section{SINTERING RESULTS OF SINGLE BEADS}

A series of tests for fusing single tracks on a $1.1 \mathrm{~mm}$ thick H13 substrate was carried out to locate suitable combinations of process parameters. The results are roughly divided into two categories in Fig. 3: one has all of the beads firmly fused on the substrate and is labelled as 'bonded', no matter what the appearance of beads; the other contains other loose beads which could not be firmly fused on the substrate and is labelled as not bonded'.

The data shows a clear trend: as the pulse width increases, higher specific energy density is required to produce bonded results. The system behaviour in the marked 'transitional region' still cannot be fully understood. It is believed that the cooling effect of fused beads may play an important role. 


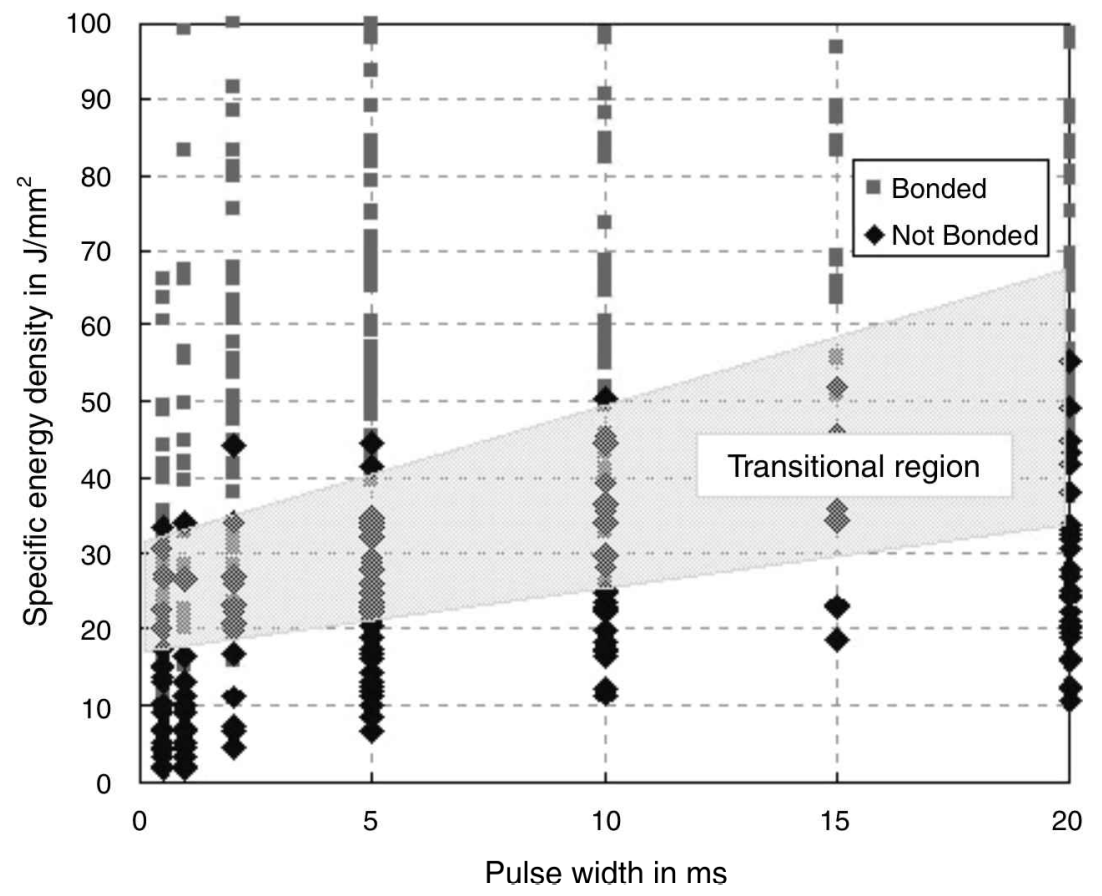

Fig. 3 Results of single tracks on the substrate presented with the defined variable 'specific energy density'

\subsection{Bead shape}

Many bead features were observed during the tests. Characteristic features are summarized in Fig. 4. They include the bulge at the start of the bead, the disrupted surface and smooth regular beads.

The bulge, usually found at the start of the bead, is thought to be related to surface tension. When the 'cold' powder bed is irradiated by the laser beam, the temperature suddenly rises and establishes a high thermal gradient in the material. Surface tension also increases. The surface tension forces are proportional to the difference in surface free energy of the melt and the substrate [4]. Consequently, molten metal tends to form a spherical bulge to reduce the surface tension. Once the scanning begins, the powder bed and substrate become

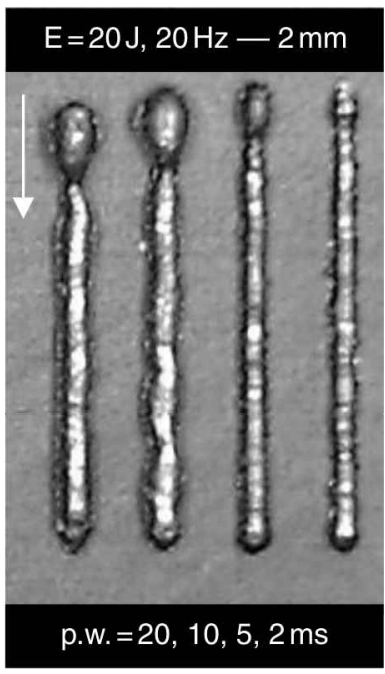

(a)

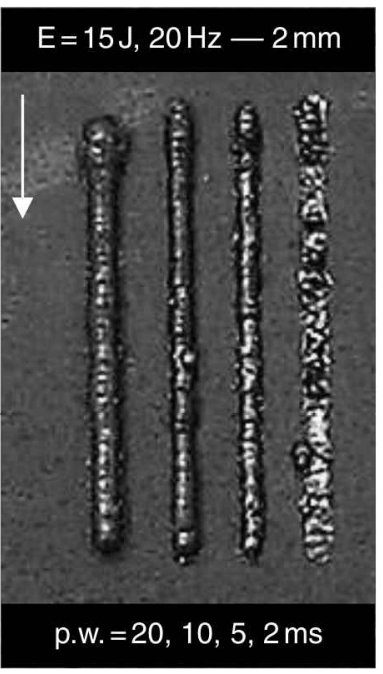

(b)

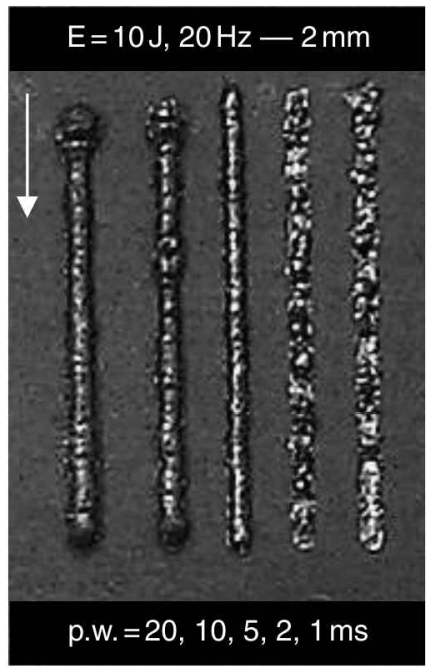

(c)

Fig. 4 Effects of pulse width on the quality of beads with a repetition rate of $20 \mathrm{~Hz}$ and (a) pulse energy of $20 \mathrm{~J}$, feed rate of $400 \mathrm{~mm} / \mathrm{min}$; (b) pulse energy of $15 \mathrm{~J}$, feed rate of $200 \mathrm{~mm} / \mathrm{min}$; (c) pulse energy of $10 \mathrm{~J}$ and feed rate of $200 \mathrm{~mm} / \mathrm{min}$. The arrows indicate the scanning direction 

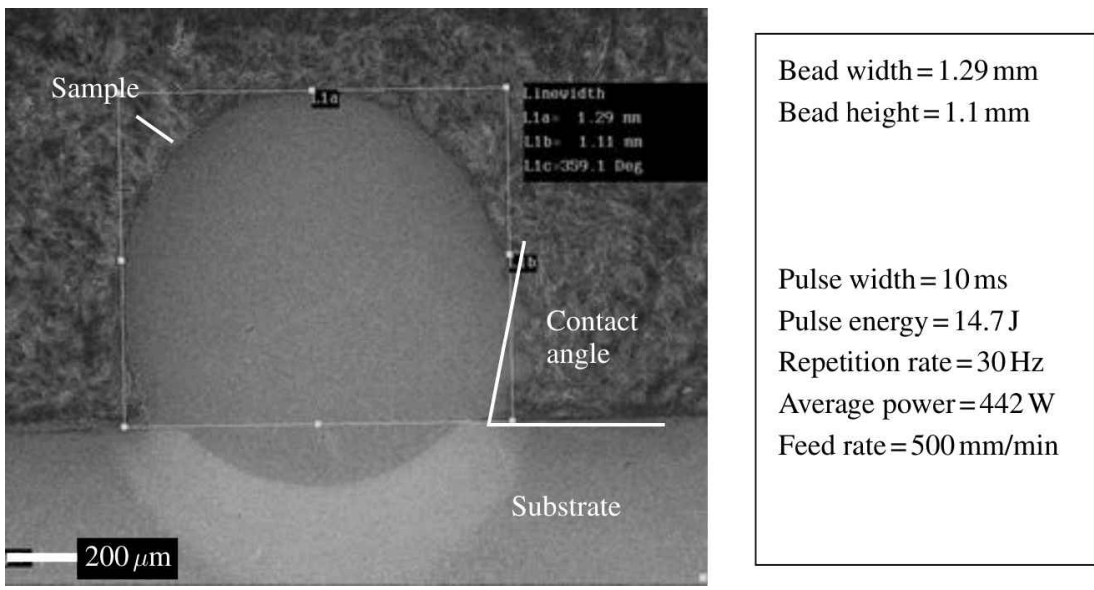

Fig. 5 Bead shape from the cross-sections of a sintered bead on the flat substrate (H13)

hot and the difference in surface free energy drops. Therefore, the effect of surface tension with regards to the formation of a bulge diminishes.

It is common to have a fine but disrupted bead when short pulse widths (less than $2 \mathrm{~ms}$ ) are applied. This may result from the relatively high peak power due to short pulse widths. Evaporation and ionization of powder forms plasma and this can cause a shock wave to be imposed on the powder bed [4]. Disruption of the powder layer results in an inhomogeneous surface texture on the bead.

Unlike laser cladding, the fused deposition has a circular contour on the substrate rather than an obtuse contact angle. The contact angle between the bead root and substrate is depicted in Fig. 5. A large contact angle is preferable to avoid pores, when successive beads are overlapped together.

To achieve fully dense sintered layers, it is essential to have a straight bead of uniform width and homogeneous surface features. The possibility of forming pores due to 'irregular' powder packing can then be minimized and the resultant layer surface can also be smoother. This will again be favourable for building up the next layer on top of it.

A further series of experiments were conducted with selected combinations of process parameters, which were narrowed down by the findings in Fig. 3. The pulse energies were set at three different levels: 15, 10 and $7.5 \mathrm{~J}$. The repetition rates were set at two levels: 20 and $10 \mathrm{~Hz}$. The table speeds were set at 600,400 and $200 \mathrm{~mm} / \mathrm{min}$ for $20 \mathrm{~Hz}$ and 300,200 and $100 \mathrm{~mm} /$ $\min$ for $10 \mathrm{~Hz}$ respectively. Each parameter setting was performed under various pulse widths from 20 , 15,10 and $5 \mathrm{~ms}$ to $2 \mathrm{~ms}$ separately. The beads had a length of $20 \mathrm{~mm}$ and the optimal combination was decided by comparing the bead width and surface features.

\subsection{Surface texture of beads}

Beads were measured over a sample length of $19.5 \mathrm{~mm}$. Beads with a bulge (usually at the start) or irregularity (e.g. fused excessive particles) were omitted to avoid possible damage to optics or obstruction of table movement due to the clearance between the laser probe and sample.

The surface profiles taken from the centre-line of beads were compared with the peak-valley value. From the point of view of processing, a minimum variation of waviness provides a 'flatter' surface for successive powder deposition. Waviness and roughness measurements were calculated from the selected surface profile and analysed with a $0.8 \mathrm{~mm}$ cut-off length and a Gaussian filter. Figure 6 shows an example of the surface profile plot obtained using this technique. The measured results are listed in Table 2.

\subsection{Bead width}

The bead width was measured at 12 positions across the whole bead length. The variance of measurements of the bead widths indicates the degree of uniformity. In this case, the less the variation, the more uniform bead width is expected.

The results in Fig. 7 show clearly that the bead width increases with an increase in pulse width, regardless of the level of the pulse energy. It was noted that the bead widths of large pulse widths (e.g. 10-20 ms) are considerably larger than a single spot size (ca. 0.9$1 \mathrm{~mm}$ ). This indicates that the effect of heat conduction in a longer pulse contributes significantly to the process of fusing powders together. 
(a)

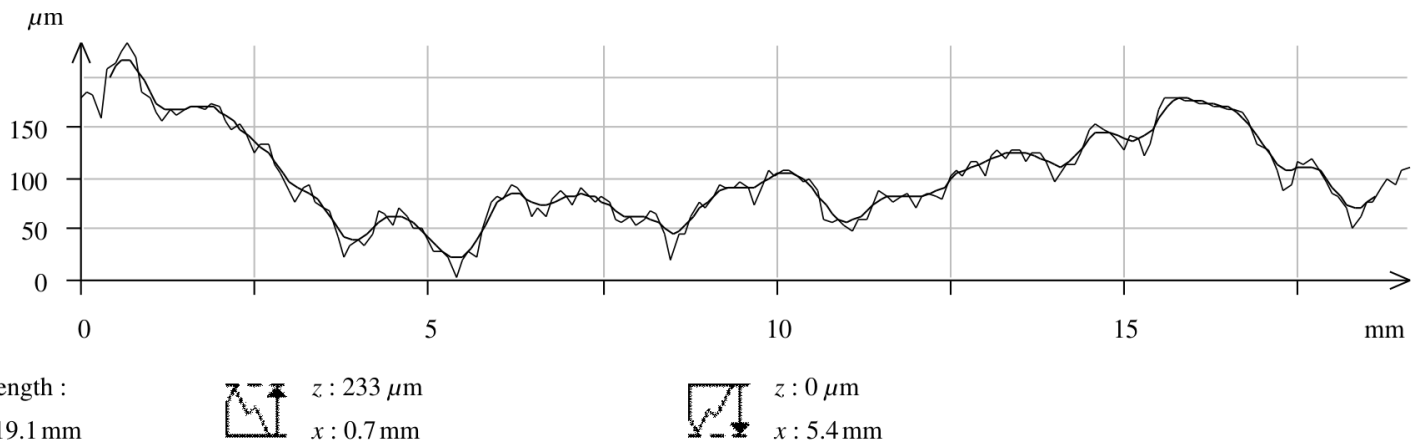

(b)

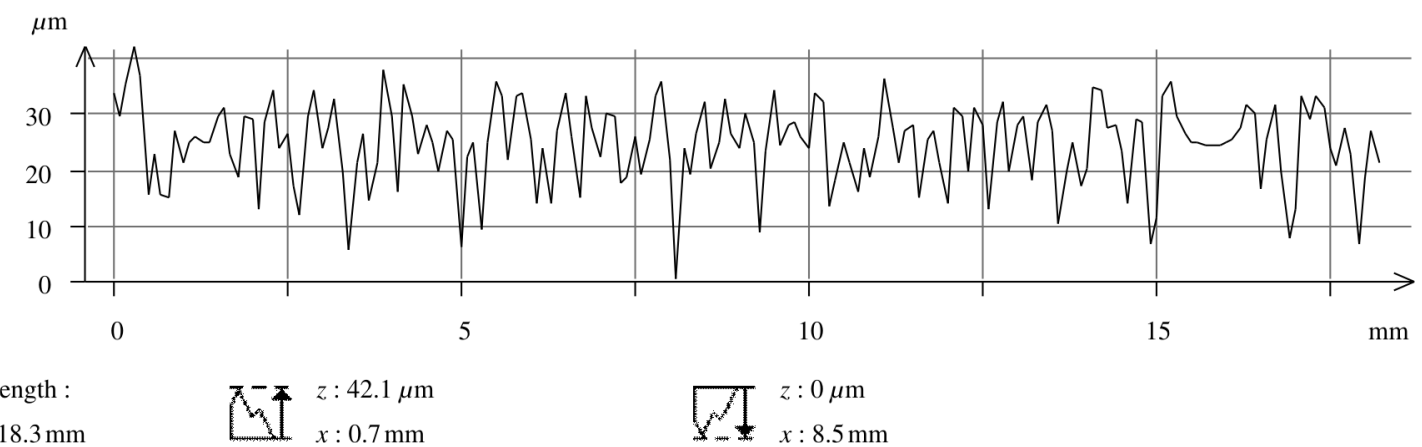

Fig. 6 (a) Waviness plot with raw measurement data; (b) roughness plot

\subsection{Selection of basic parameters}

Beads produced with a repetition rate of $20 \mathrm{~Hz}$ usually have a bulge at the start or insufficient bonding. The $20 \mathrm{~Hz}$ results are not presented because of greater surface waviness and roughness. In general, samples made with a repetition rate of $10 \mathrm{~Hz}$ had a lower waviness and roughness, especially with a pulse width of $5 \mathrm{~ms}$. The difference between results of pulse energy of 10 or $15 \mathrm{~J}$ was not evident with a repetition rate of
$10 \mathrm{~Hz}$, while insufficient bonding was obtained with $7.5 \mathrm{~J}$.

Though beads produced with a pulse width of $2 \mathrm{~ms}$ usually had a low variance in bead width, disrupted surfaces made it less suitable in processing. The variance of bead widths of less than $0.01 \mathrm{~mm}$ was mainly obtained by using a pulse width of $5 \mathrm{~ms}$. These findings indicate that a pulse width of $5 \mathrm{~ms}$ with a pulse energy of $10 \mathrm{~J}$ can produce a flatter, straight bead with uniform width. All of these characteristics are essential for

Table 2 Results of surface features with the highlighted area representing the selected optimal combinations of process parameters

\begin{tabular}{lllllllll}
\hline $\begin{array}{l}\text { Feed rate, } \\
(\mathrm{mm} / \mathrm{min})\end{array}$ & $\begin{array}{l}\text { Pulse width } \\
(\mathrm{ms})\end{array}$ & $\begin{array}{l}\text { Pulse } \\
\text { energy } \\
(\mathrm{J})\end{array}$ & $\begin{array}{l}\text { Pulse } \\
\text { frequency } \\
(\mathrm{Hz})\end{array}$ & $\begin{array}{l}\text { Average } \\
\text { power } \\
(\mathrm{W})\end{array}$ & $\begin{array}{l}\text { Average waviness } \\
\text { height }(\mu \mathrm{m})\end{array}$ & $\begin{array}{l}\text { Average } \\
\text { roughness }(\mu \mathrm{m})\end{array}$ & $\begin{array}{l}\text { Average bead } \\
\text { width }(\mathrm{mm})\end{array}$ & $\begin{array}{l}\text { Average variance } \\
\text { of bead }(\mathrm{mm})\end{array}$ \\
\hline 200 & 15 & 15.1 & 10 & 151 & 399.50 & 8.83 & 1.5474 & 0.0778 \\
300 & 15 & 15.1 & 10 & 151 & 386.00 & 13.20 & 1.3601 & 0.0591 \\
300 & 10 & 15.1 & 10 & 150 & 222.5 & 5.34 & 1.2959 & 0.0221 \\
100 & 5 & 15.1 & 10 & 151 & 256.5 & 5.77 & 1.2520 & 0.0098 \\
200 & 5 & 15.1 & 10 & 151 & 132.5 & 6.04 & 0.9996 & 0.0037 \\
300 & 5 & 15.1 & 10 & 151 & 152.0 & 12.57 & 0.9941 & 0.0074 \\
100 & 10 & 10.2 & 10 & 102 & 522.5 & 10.30 & 1.3901 & 0.1089 \\
200 & 10 & 10.2 & 10 & 102 & 349.0 & 11.25 & 1.4164 & 0.0462 \\
300 & 10 & 10.2 & 10 & 102 & 455.0 & 18.40 & 1.1696 & 0.0293 \\
100 & 5 & 10.2 & 10 & 102 & 346.0 & 5.08 & 1.1220 & 0.0060 \\
200 & 5 & 10.2 & 10 & 102 & 231.0 & 5.99 & 0.9505 & 0.0071 \\
300 & 5 & 10.2 & 10 & 102 & 123.0 & 10.17 & 0.9151 & 0.0057 \\
100 & 10 & 7.5 & 10 & 75 & 181.5 & 5.99 & 1.7124 & 0.0368 \\
100 & 5 & 7.5 & 10 & 75 & 350.5 & 7.06 & 1.1625 & 0.0230 \\
200 & 5 & 7.5 & 10 & 75 & 260.0 & 9.09 & 1.1912 & 0.0127 \\
\hline
\end{tabular}


(a) Pulse energy $=10 \mathrm{~J}$ at $10 \mathrm{~Hz}$

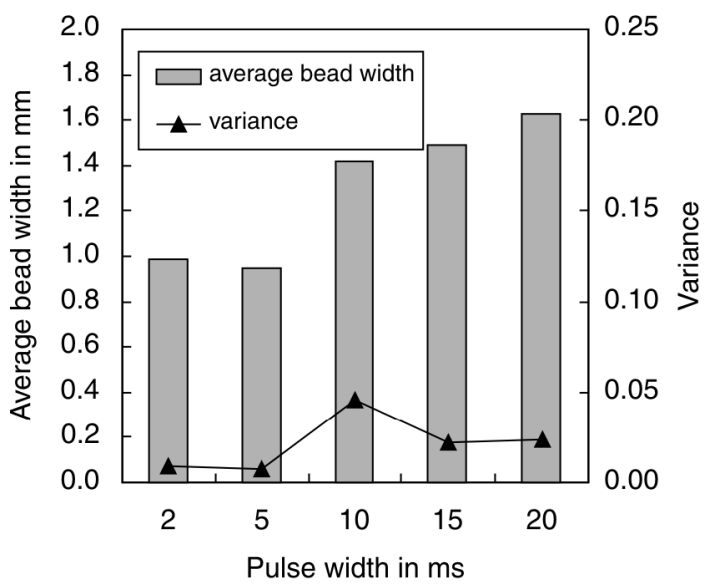

(b) Pulse energy $=15 \mathrm{~J}$ at $20 \mathrm{~Hz}$

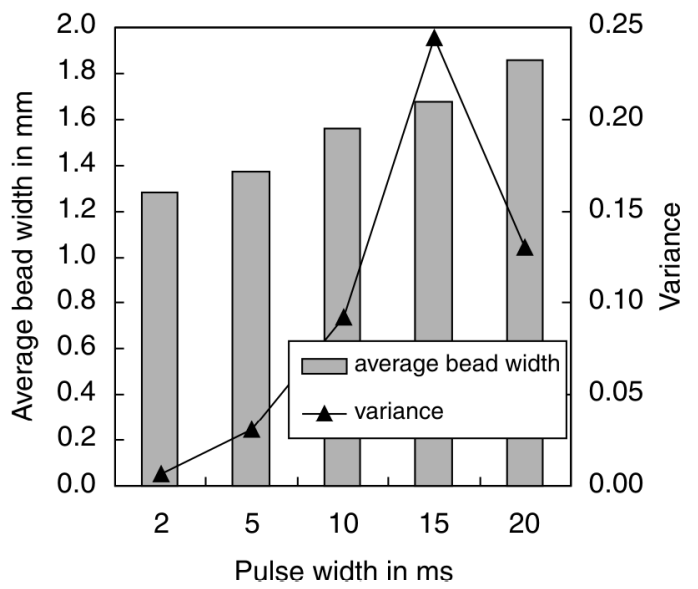

Fig. 7 Measurements of bead widths and their variances with two different pulse energy levels and repetition rates; feed rate $200 \mathrm{~mm} / \mathrm{min}$

creating multilayered structures. The selected process parameters highlighted in Table 2 present a good combination of surface features, bead width and variance, and were applied as a standard setting in all following experiments of sintering layered structures, if not otherwise specified. Some results are left out due to the formation of bulge, disrupted surface or no bonding to the substrate.

\section{EFFECTS OF THE SYSTEM PARAMETERS ON SINTERING RESULTS}

\subsection{Pulse width}

With constant pulse energy, the penetration depth often increases with a decrease in pulse width. This corresponds to higher peak power but is accompanied by an increase in porosity and a reduction in quality. In general, the bead width increases with increasing pulse width. This can also be seen from Figs 4 and 7, where beads scanned with shorter pulse widths (e.g. 1 and $2 \mathrm{~ms}$ ) produce a sputtered surface. Evaporation and ionization of powder forms plasma, which can cause a shock wave to be imposed on the powder bed [4]. This disruption of the powder layer results in an inhomogeneous surface texture on the bead. An impact sound on the substrate associated with laser pulsing could be heard while conducting experiments on short pulse widths. This can be improved by reducing the laser energy, if short pulse widths are inevitable, for example, in creating some fine features.

It was also noticed that beads produced by larger pulse widths (e.g. 15-20 ms) are usually associated with less regular widths, compared to those by shorter pulse widths. Larger pulse widths mean a longer laser-on time. Under the same conditions, longer pulse widths allow metal fluid to have more time to flow 'freely' and heat conduction in radial and axial directions also has a larger effect on the bead formation.

\subsection{Pulse energy}

Pulse energy mainly decides whether the beads are firmly bonded on the substrate. Insufficient pulse energy also produced small contact angles between the bead and the substrate which was undesirable. Too much pulse energy is likely to distort the substrate after only a few scans.

\subsection{Repetition rate}

Unlike in a continuous laser, the laser power of a pulsed laser is a product of the repetition rate and pulse energy, where the latter variable is dependent on the pulse width. Compared with other variables, the repetition rate has a less evident effect on the fused results. High repetition rates shorten the life of flash lamps, but increase the throughput of the whole process. It is necessary to set the repetition rate of the laser in agreement with the feed rate of the $X / Y$ table. The repetition rate can also influence the cooling between pulses.

\subsection{Feed rate of the $X / Y$ table}

The broken beads and beads without sufficient bonding to the substrate, as seen in Fig. 8, are believed to be as a result of too fast a table speed (with respect to a fixed laser power) or a low laser power (with respect to a fixed table speed). To optimize the results, the repetition rate (i.e. pulse frequency) needs to be taken into account with any change of feed rate. If the feed rate is low, laser 


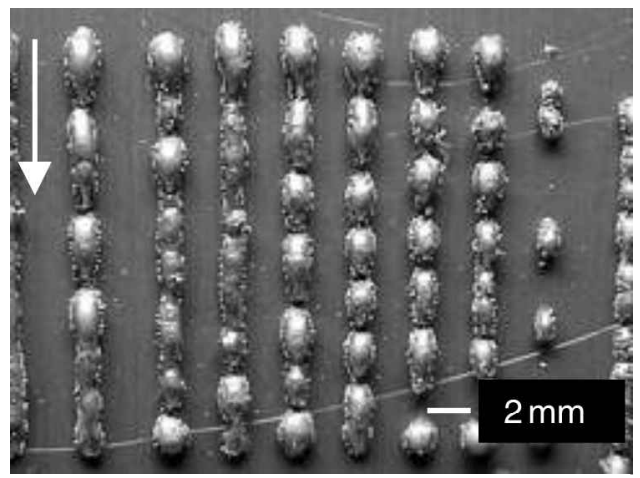

Fig. 8 Discontinuous beads when the feed rate is too high. The arrow indicates the scanning direction

energy input can sometimes be too high, resulting in distortion of the workpiece. If the feed rate is set too high, the bead becomes discontinuous due to Rayleigh instability in the liquid metal [17], as seen in Fig. 8. If the feed rate increases, the repetition rate needs to be increased as well, and vice versa.

At lower table feed rates, there is more choice in combining different parameters (e.g. pulse width, pulse energy, repetition rate, etc.) to give reasonable results within a large window of specific energy density. In contrast, the system can only provide limited options as the speed increases and could often not produce 'bonded' beads. The system may become more 'sensitive' and require deliberation in choosing the combination of parameters.

\section{SINTERING LAYERED STRUCTURES}

Like any other solid freeform fabrication (SFF) technology, layered structures can be produced by repeatedly building the elemental forms. In the current process, each scan needs to be partially overlapped to avoid any porosity. Moreover, the scanning pattern defines how the laser hatches the cross-sections and is also vital to manual layering of new powder (in the current process) and the thermal history of materials which influences the material properties.

\subsection{Scan spacing and scanning patterns}

Various factors become important and need to be considered when the powder fusion process moves from a single bead to a layer, i.e. scan spacing in overlapping beads and scanning strategy. A scanning strategy can be understood as a systematic approach to scan (or deposit) the material in such a way as to build up material layers. This includes the scanning directions and the arrangement of the sequence of scans. It also affects the allowed cooling time of the fused object.

For a single layer of five overlapped beads, the four scanning patterns shown in Fig. 9 were proposed to be studied. It should be noted that the four different scanning patterns also result in different lengths of processing time. The laser scans in double-scan spacing in patterns 3 and 4 and travels back to fill the space left from the previous scan sequence. In the examples of Fig. 9, pattern 2 has a minimum airtime.

In an example with a scan spacing of $0.5 \mathrm{~mm}$, four patterns were performed and the samples were crosssectioned to measure the deposited thickness. The crosssections are compared in Fig. 10. It is noted that:

1. Pattern 3 was superior in achieving a greater layer thickness of deposition, though these odd-even scan patterns produced a wavy surface.

2. The results from patterns 1 and 2 share similar surface features. Similarly, patterns 3 and 4 produce parallel results.

3. In patterns 1 and 2 , the effect of one-sided reflection of laser irradiation due to overlapping made the neighbouring powder spatter and the initially levelled powder surface became uneven. The uneven surface and subsequently created void might cause problems in producing the next overlapped beads. The overlapped thickness became a minimum after a few scans.

Due to the similarity between scan patterns 1 and 2 and patterns 3 and 4 , the effects of various scan spacings in

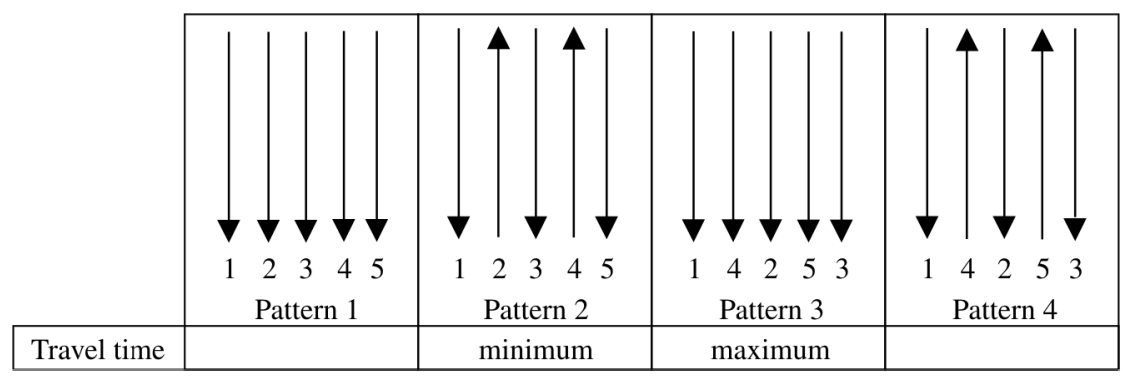

Fig. 9 Four different scanning strategies to be studied. The numbers indicate the scanning sequence while the arrows represent the scanning directions 


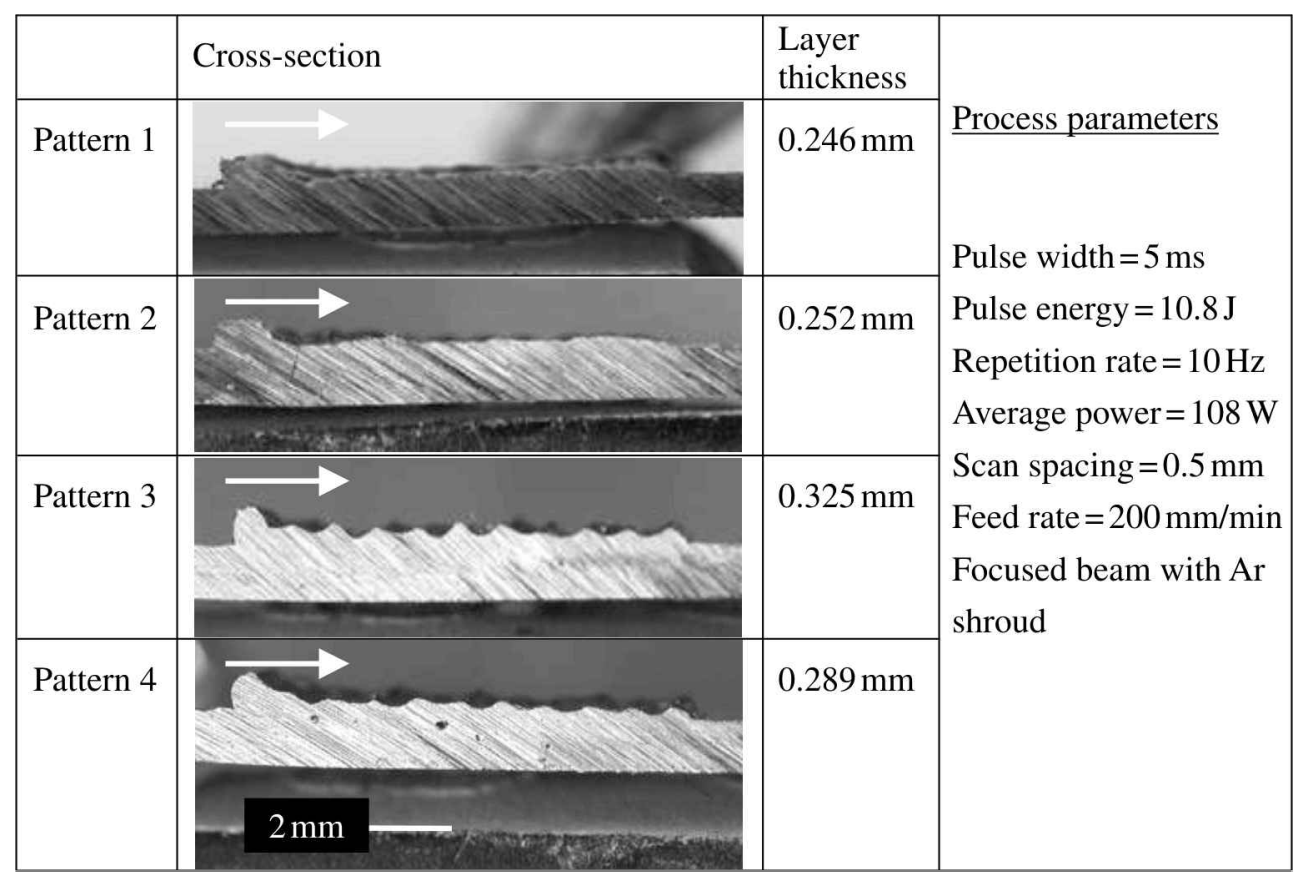

Fig. 10 Comparison of cross-sections of four patterns and the deposited layer thickness with an indication of the scanning direction

scan patterns 1 and 3 were studied in detail. The samples contained a single layer of deposition and were crosssectioned after 20 scans; the size of the sample changed as the scan spacing varied. The processing parameters were the same as mentioned in Fig. 10, except that the scan spacing varied from 0.8 to $0.3 \mathrm{~mm}$.

The layer thickness deposited by scanning pattern 1 decreased with the increasing scan spacing, as shown in Fig. 11. On the other hand, the average layer thickness produced by scanning pattern 3 increased with the increasing scan spacing. In pattern 3 , as the scan spacing decreased the scans increasingly overlapped and this

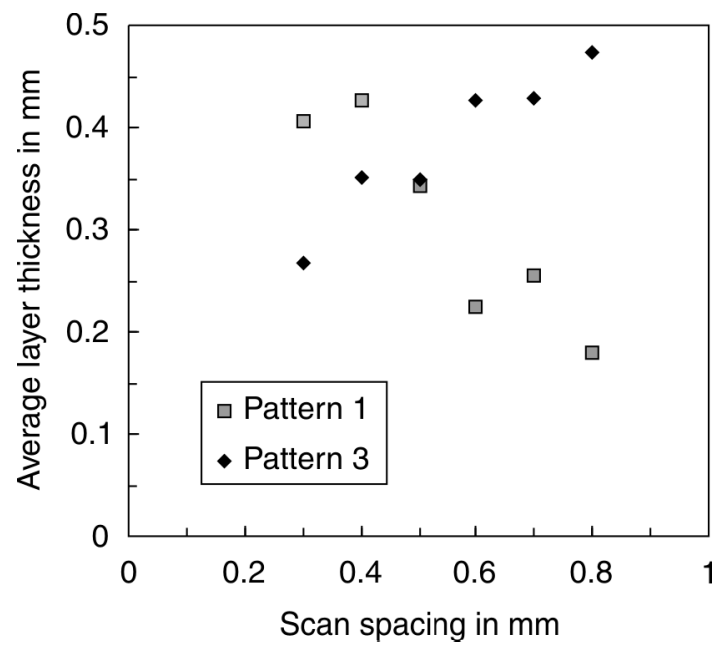

Fig. 11 Average layer thickness versus scan spacing in scan patterns 1 and 3 became similar to laser remelting of the surface. The average thickness of the fused layer in both scan patterns was less than $0.5 \mathrm{~mm}$ and suggested that the initial layer thickness of powder should be reduced to ensure full bonding in the multilayered structures.

\subsection{Occurrence of porosity}

By examining the cross-sections of porous samples, it can be seen that the pores are mainly located at the roots of beads where there might be a dead zone for packing powder if the contact angle is relatively small. Examples of deficient interlayer bonding due to large layer thickness (using $1 \mathrm{~mm}$ stacking frames) are shown in Fig. 12. Repeated wavy surface features can also cause problems with subsequent deposited layers, as seen from these examples.

Pores were found in the cross-sections of some samples. Many factors can cause pores:

(a) gas trapped in the melt due to improper arrangement of the shielding gas or gas pressure;

(b) gas absorption due to chemical affinity between the shielding gas and the molten metal;

(c) poor wetting between the melt and solid;

(d) low packing density and insufficient powder due to surface irregularity or a small contact angle between the solidified bead and substrate;

(e) insufficient bonding between layers due to low energy input or a thick powder layer. 


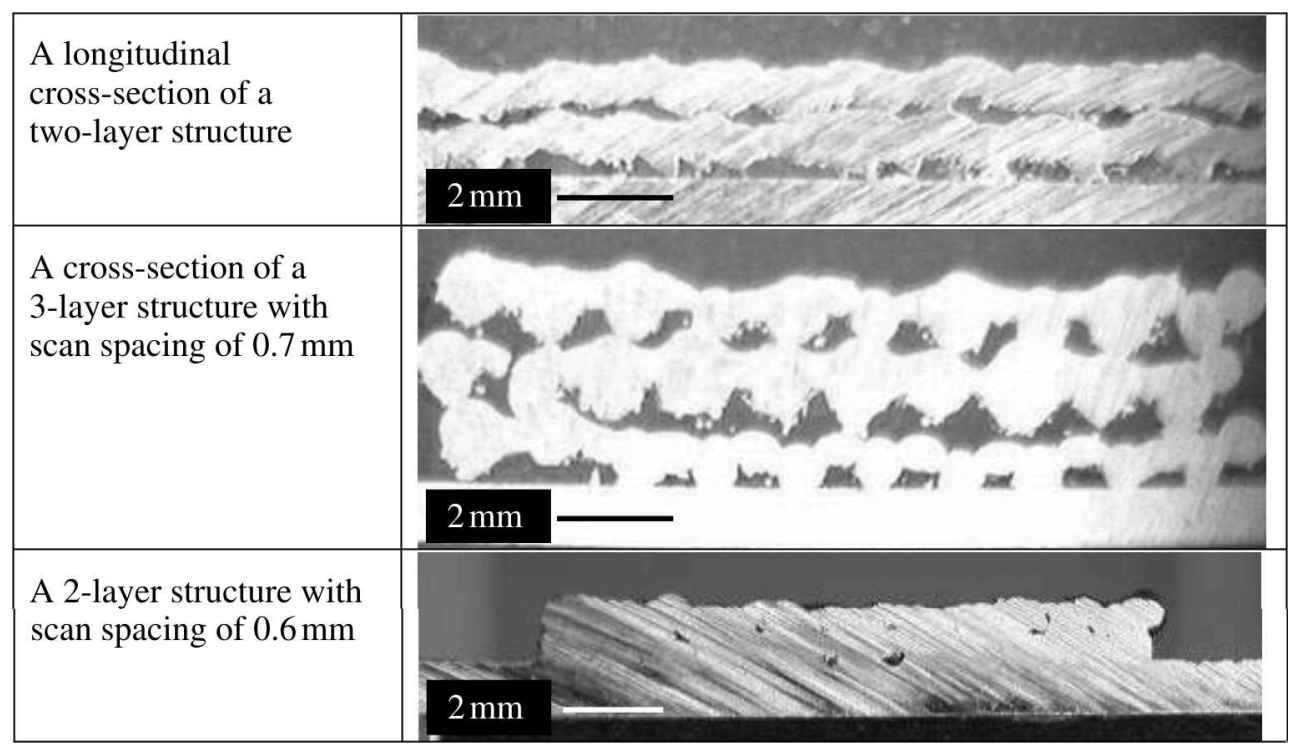

Fig. 12 Cross-sections of samples with a lack of interlayer bonding

One way to improve this phenomenon is to pack more powder between the scans in order to increase the packing density in these problematic areas. This led to a new scanning strategy where new powder was added between the odd and even scanning sequences in scanning pattern 3 to give a more uniform layer. This double-recoating method also involved reducing the layer thickness from 1 to $0.4 \mathrm{~mm}$ and the eventual bonded layer thickness became $0.3 \mathrm{~mm}$.

\subsection{Multilayered structure with a modified scan pattern}

Some samples of a multilayered structure and cubes were fabricated to demonstrate the feasibility of the whole process. After scanning the odd numbers of paths in scan pattern 3, new powder was added to fill in the voids and levelled. This new powder was then scanned to form a solid layer with previously deposited beads. A few new stacking frames with thicknesses of 250 and $400 \mu \mathrm{m}$ were made and used in creating cubes, as shown in Fig. 13.

Experiments of building up similar structures with cross-hatching (i.e. alternating scanning directions in layers) are envisaged. Figure 14 shows the characteristics of the surface and the cross-section of a two-layer structure. Further mechanical tests on these samples may be necessary in order to compare the material properties with the wrought material. Analyses on the microstructure and the influence of surface oxidation are ongoing.
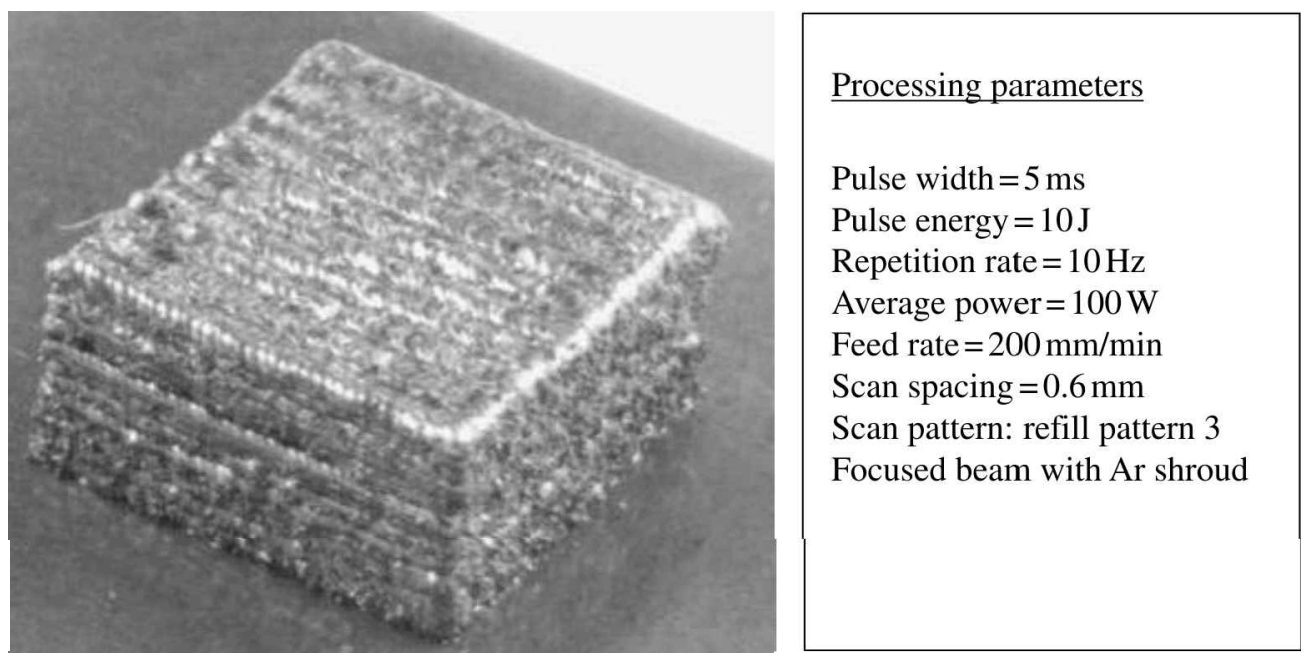

Fig. 13 Cube $(12 \mathrm{~mm} \times 12 \mathrm{~mm} \times 6 \mathrm{~mm})$ fabricated with a reduced layer thickness and modified scanning pattern 


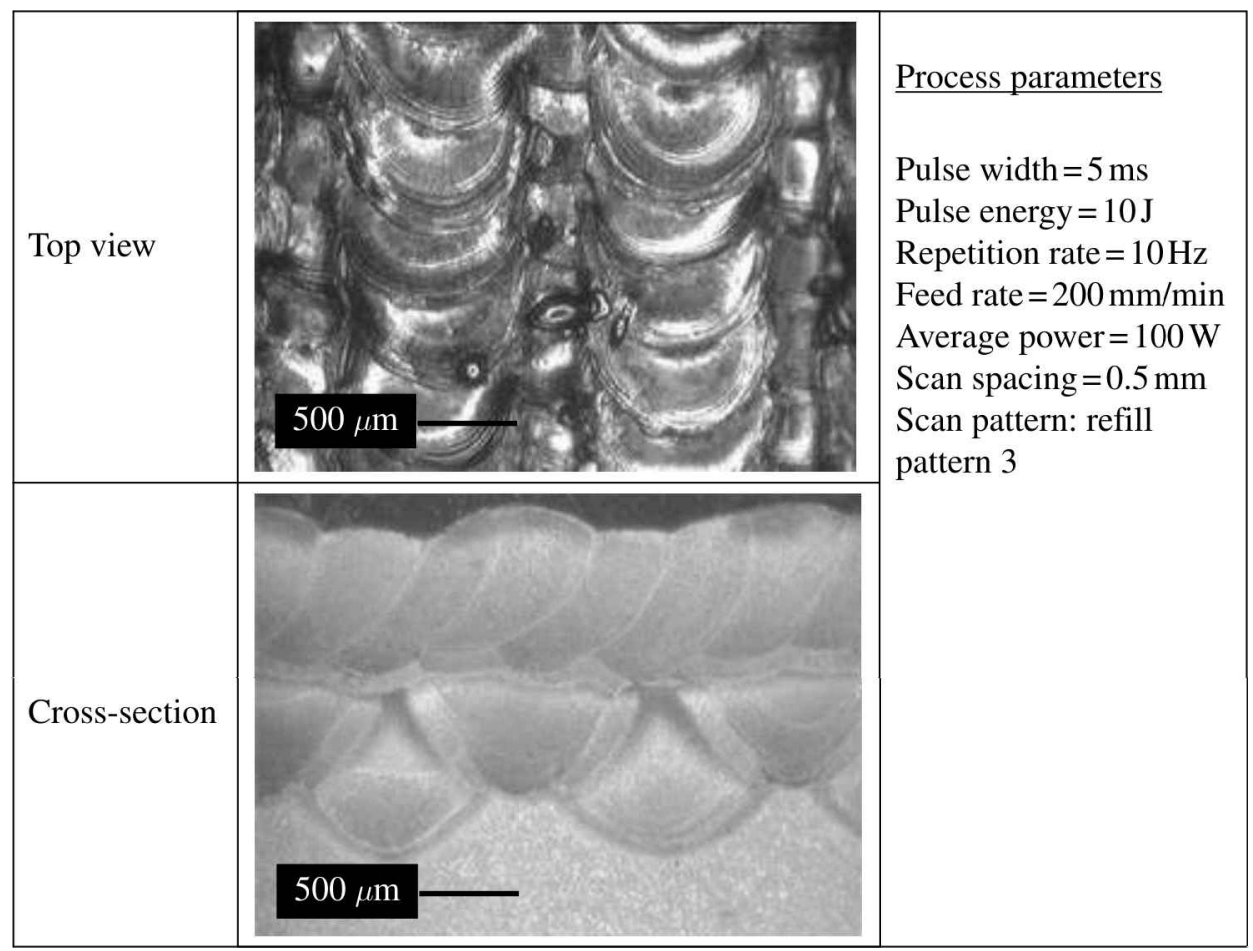

Fig. 14 Close-up pictures of a two-layered structure with cross-hatching

\section{CONCLUSIONS}

The fusing of a dense metal part from tool steel powder was demonstrated. Powder was fused with a pulsed Nd:YAG laser. Single beads on the substrate were first produced to provide an overview of the processing possibility of the system. Refined combinations of system parameters were selected to locate the optimal settings, which were then applied to the following experiments. The selection of parameters was done by comparing measurements of the bead features, i.e. waviness and roughness, bead width and its variance. The effects of system parameters on the bead quality are discussed.

Four scan patterns and various scan spacings were tested on building overlapped beads. It was concluded that the scan pattern with double-scan spacing and refill of powder could create a dense structure. Multilayered structures were consequently produced. The microstructures and mechanical properties of these samples are currently being investigated and further work is being carried out to produce fully dense complex shapes.

Future work will investigate the mechanical properties of pre-forms and inclusion of non-metallic particles, as well as the suitability of the material for hot working dies.

\section{ACKNOWLEDGEMENTS}

Work was undertaken as part of the Engineering and Physical Sciences Research Council (EPSRC)/industry funded Grant GR/N21703/01, Direct Fabrication of Complex Functionally Graded Metal Structures Project managed by Loughborough University. The authors would like to thank the EPSR C, the academic partners (The University of Liverpool, UMIST and Queen Mary and Westfield College) and the industrial partners (GSI LUMONICS and Osprey Metals) for supporting the authors.

\section{REFERENCES}

1 Kruth, J. P., Lu, M. C. and Nakagawa, T. Progress in additive manufacturing and rapid prototyping. Ann. CIRP, Mfg Technol., 1998, 47(2), 525-540.

2 Meiners, W., Wissenbach, K. and Poprawe, R. Direct selective laser sintering of steel powder. In Proceedings of the LANE'97, University of Erlangen, Germany, September 1997, pp. 615-622.

3 Hauser, C., Childs, T. H. C., Dalgarno, K. W. and Eane, R. B. Atmospheric control during direct selective laser sintering of stainless steel 314 S powder. In Proceedings of 
the Solid Freeform Fabrication Symposium, University of Texas, Austin, Texas, August 1999, pp. 273-280.

4 Morgan, R., Sutcliffe, C. J. and O'Neill, W. Experimental investigation of nanosecond pulsed $\mathrm{Nd}$ :YAG laser remelted pre-placed powder beds. Rapid Prototyping J., 2001, 7(3), 159-172.

5 O'Neill, W., Sutcliffe, C. J., Morgan, R. and Hon, K. K. B. Investigation of short pulse $\mathrm{Nd}$ :YAG laser interaction with stainless steel powder beds. In Proceedings of the Solid Freeform Fabrication Symposium, University of Texas, Austin, Texas, August 1998, pp. 147-160.

6 Bourell, D. L., Marcus, H. L., Barlow, J. W. and Beamen, J. J. Selective laser sintering of metals and ceramics. Int. J. Powder Metallurgy, 1992, 28(4), 369-381.

7 Weerasinghe, V. M. and Steen, W. M. Computer simulation model for laser cladding. In Transport Phenomena in Materials Processing, 1983, p. 15 (American Society of Mechanical Engineers, New York).

8 Weerasinghe, V. M. and Steen, W. M. Laser cladding with pneumatic powder delivery. In Applied Laser Tooling (compiled by O. D. D. Soares and M. Perez-Amor), 1987, p. 183 (Martinus Nijhoff Publishers, Dordrecht, The Netherlands).

9 Murphy, M., Lee, C. and Steen, W. M. Studies in rapid prototyping by laser-surface cladding. In ICALEO 93Laser Materials Processing (complied by P. Denney, I. Miyamto and B. L. Mordike), 1994, p. 882 (SPIE and International Society of Optical Engineering, Bellingham, Washington).

10 Karapatis, N. P., van Griethuysen, J.-P. S. and Glardon, R.
Direct rapid tooling: a review of the current research. Rapid Prototyping J., 1998, 4(2), 77-89.

11 Griffith, M. L., Keicher, D. M., Atwood, C. L., Romero, J. A., Smugeresky, J. E., Harwell, L. D. and Greene, D. L. Free form fabrication of metallic components using laser engineered net shaping (LENS ${ }^{\mathrm{TM}}$ ). In Proceedings of the Solid Freeform Fabrication Symposium, University of Texas, Austin, Texas, August 1996, pp. 125-131.

12 Lewis, G. K., Milewski, J., Thoma, D. B. and Nemec, R. B. Properties of near-net shape metallic components made by the directed light fabrication process. In Proceedings of the Solid Freeform Fabrication Symposium, University of Texas, Austin, Texas, August 1997, pp. 513-520.

13 Mazumder, J., Choi, J. and Nagarathnam, K. The direct metal deposition of H13 tool steels for 3-D components. J. Metals, May 1997, 49, 55-60.

14 Klocke, F., Wirtz, H. and Meiners, W. Direct manufacturing of metal prototypes and prototype tools. In Proceedings of the Solid Freeform Fabrication Symposium, University of Texas, Austin, Texas, August 1996, pp. 141-148.

15 Dave, V. R., Matz, J. and Eagar, T. Electron beam solid freeform fabrication of metal parts. In Proceedings of the Solid Freeform Fabrication Symposium, University of Texas, Austin, Texas, August 1995, pp. 64-71.

16 Wohlers, T. Wohlers Report-Annual Worldwide Progress Report, 2001.

17 Niu, H. J. and Chang, I. T. H. Selective laser sintering of gas atomized M2 high speed steel powder. J. Mater. Sci., 2000, 35, 31-38. 